\title{
Evaluation of an Automated Method for Analysing the Electromyogram
}

\author{
R. E. P. SICA, A. J. McCOMAS AND J. C. D. FERREIRA
}

SUMMARY: An automated system, incorporating the ANOPS-101 mini-computer, has been used to analyse the EMG. The vastus medialis (VM) and biceps brachii $(B B)$ muscles were studied in 28 controls, 16 patients with myopathies, and in 26 patients with denervating disorders. For each muscle mean values were computed for the durations and numbers of phases of muscle action potentials; the mean density and amplitude of the deflections in the interference pattern were also measured. $A$

RESUME: Nous avons utilisé un système automatique, employant le mini-ordinateur ANOPS-101, pour l'analyse du EMG. Les muscles vastes median (VM) et biceps (BB) furent étudiés chez 28 contrôles, 16 patients avec myopathies et 26 patients avec dénervation. Pour chaque muscle des valeurs furent obtenues pour la durée et le nombre de phases de potentiels d'actions musculaires; nous avons aussi mesuré la densité moyenne et l'amplitude des déflections enregistrées sur le pattern higher incidence of abnormalities could be detected in myopathic than in neuropathic disorders; for both conditions the incidence was significantly greater in BB than in $V M$. For the diagnosis of denervation the most useful measurement was that of potential duration; for the detection of myopathies amplitude determinations were also very useful. The present results have been compared with those of other published studies in which automatic EMG analysis has been employed.

d'interférence. Nous avons trouvé une incidence plus élevée d'anomalies dans les désordres myopathiques que neuropathiques; dans les deux conditions l'incidence d'anomalies était plus grande dans les muscles BB que VM. Pour le diagnostic de dénervation, la mesure la plus utile de dénervation fut celle de la durée du potentiel; pour la détection des myopathies la mesure la plus utile fut celle de l'amplitude. Nous comparons enfin nos résultats avec ceux de la littérature.
From the Medical Research Council Group in Developmental Neurobiology, McMaster University, Hamilton, Ontario, Canada.

Reprint requests to: Dr. Alan J. McComas, Department of Neurology, Room 4U7, McMaster University Medical Centre, 1200 Main Street West, Hamilton, Ontario, Canada, L8S 4 J9.

\section{INTRODUCTION}

Following the recognition that neuropathic and myopathic disorders produce contrasting abnormalities in the electromyogram, several attempts have been made to devise methods of analysis which are both quantitative and automatic (Walton, 1952; Rose and Willison, 1967; Kunze, 1973; Lee and White, 1973). In the present study we have evaluated a method which makes use of a mini-computer with fixed programmes, the ANOPS-101 (Warsaw Institute of Technology, Poland). In addition to performing conventional averaging and pulse interval analyses, this instrument is equipped with EMG programmes which enable it to analyse the durations, amplitudes, and polyphasicity of individual motor unit potentials together with the density of the volitional interference pattern. The results are then displayed as histograms on a cathode ray tube. Previous accounts of the use of the instrument have been given by Kopec, Hausmanowa-Petrusewicz, Rawski and Wolynski (1973) and by Kopec and Hausmanowa-Petrusewicz (1976), in whose laboratory this system of analysis was devised. These authors have found their method to be sufficiently sensitive not only to differentiate most patients with overt denervation or myopathy from normal, but also to distinguish abnormalities in a high proportion of carriers of Duchenne muscular dystrophy. In the present study the precision of analysis has been enhanced by passing the output from the computer into an electronic calculator and thereby deriving numerical values for the various statistical procedures. Like Kopec and Hausmanowa-Petrusewicz (1976), we have analysed the electromyogram in the proximal musculature of the limbs 
and in this paper the findings for the vastus medialis (VM) and biceps brachii (BB) are described. Observations on the intrinsic muscles of the hands and feet have been presented elsewhere and have been compared with results obtained by motor unit counting (McComas and Sica, 1978).

\section{METHODS}

\section{Controls:}

\section{Subjects}

Twenty-eight subjects, in good health with no history of neurological disorders, volunteered to serve as controls; a financial reward was given. The ages of the subjects, 14 of whom were male, ranged from 19 to 58 years. Informed consent for the procedure was obtained from each of the subjects and the study had the approval of the Ethics Committee at McMaster University.

\section{Myopathy:}

Fifteen patients with muscular dystrophy, 8 of whom were male, were examined; their ages ranged from 21 to 58 years. Ten patients had limb-girdle muscular dystrophy, three had myotonic dystrophy, and the remaining two patients had Duchenne muscular dystrophy. Another patient, a woman of 60 , had a one-year history of polymyositis associated with scleroderma.

\section{Neuropathy:}

Twenty-six patients, 16 of whom were male, had denervating disorders. Three of the subjects were selected solely on account of their ages. Aged 65,68 , and 70 , respectively, they would have been susceptible to the neuropathic changes which are known to accompany ageing (Campbell, McComas and Petito, 1973). The remaining 23 subjects were all patients aged between 22 and 60 years. The diagnosis was motoneuron disease in 9 patients and spinal muscular atrophy in 3. Two patients had chronic idiopathic peripheral neuropathies while the remaining 9 patients had clinical evidence of lumbosacral and/or cervical root compression with probable involvement of the $\mathrm{L} 4$ and the $\mathrm{C} 5$ and C6 roots, respectively. All patients, myopathic and neuropathic, had been referred for electromyography by another physician.

\section{ELECTROMYOGRAPHY}

With the subject lying supine upon a couch, the vastus medialis and biceps brachii muscles were investigated using a coaxial electrode (Disa type 9013L0501). By altering the axis of the needle (the tip lying subcutaneously), it was possible to make a number of tracks into a muscle belly through one or two skin punctures. A superficial and a deep recording were made in each track, thereby enabling $8-10$ sites to be studied in each muscle; the sites were separated from each other by at least $1 \mathrm{~cm}$. The position of the needle was adjusted only if it was not possible to detect sharply-rising potentials on a cathode ray oscilloscope during weak voluntary contraction.

The biceps was examined at, or just distal to, its region of maximal convexity; the vastus was explored in the middie third of its long axis. The knee was kept fully extended throughout the analysis of vastus activity; for maximal effort the subject was instructed either to 'tighten the knee' or to 'press the knee into the couch'. Single motor unit discharges in the biceps were examined with the elbow completely extended; the maximal interference pattern was obtained with the elbow flexed to $90^{\circ}$ and the forearm supinated, the observer providing resistance to further flexion.

The muscle action potentials were fed through a pre-amplifier with a flat frequency response between $3 \mathrm{~Hz}$ and $10 \mathrm{kHz}$ and thence into the ANOPS101 computer; at the same time the potentials were inspected on a cathode ray oscilloscope (Hewlett-Packard, model 141B). The output from the ANOPS computer was entered into a desk top calculator (Hewlett-Packard $9810 \mathrm{~A})$ which was used to determine the means and standard deviations of each of the muscle action potential parameters (see below). At the same time the histographic display provided by ANOPS-101 was drawn out by an $\mathrm{X}-\mathrm{Y}$ plotter (Hewlett-Packard type 9862A).

DETERMINATION OF MUSCLE ACTION POTENTIAL PARAMETERS

\section{Duration:}

One hundred and twenty-eight potentials were analysed in each of eight sites in the muscle belly, yielding

\section{BICEPS BRACHII}

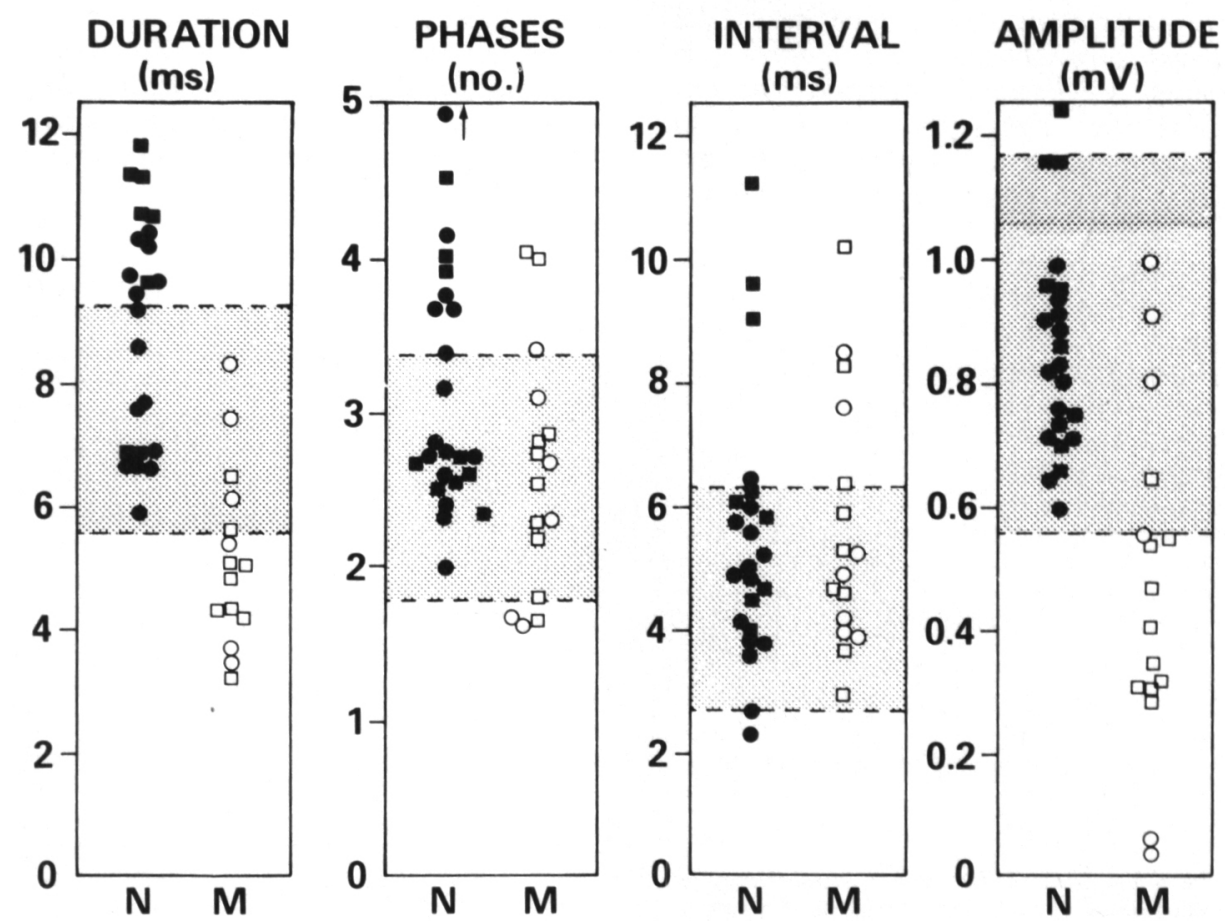

Figure 1-Biceps brachii (BB). Muscle action potential measurements in patients with neuropathic (N) and myopathic (M) disorders; 95 percent confidence limits for controls shown by stippling. Patient categories as follows: $\square$, motoneuron disease; $\bullet$ other neuropathies; [] , limbgirdle dystrophy, $O$, other myopathies. 
a total of 1,024 potentials. At each site the potentials were generated by $2-4$ motor units firing repeatedly during weak voluntary contraction. At a gain of $\overline{5}, 0 \overline{0} 0 \mathrm{x}$ a potential was accepted for measurement only if its amplitude was greater than $100 \mu \mathrm{V}$ ('decision' level); the duration was measured only for that part of the potential which exceeded $20 \mu \mathrm{V}$ ('detection' level; see Fig. 1 of Kopec and HausmanowaPetrusewicz, 1976). If unusually small potentials predominated as a result of disease, the amplification was doubled; the detection and decision levels were then $50 \mu \mathrm{V}$ and $10 \mu \mathrm{V}$ respectively, while phases greater than $20 \mu \mathrm{V}$ were measured (see below). The durations were measured with an accuracy of 0.5 $\mathrm{ms}$ irrespective of the gain setting.

\section{Phases:}

The same 1,024 potentials (above) were simultaneously examined for complexity. A phase was recognized and counted each time a potential changed its polarity by more than 40 $\mu \mathrm{V}$.

\section{Interference pattern:}

Using a pre-amplifier gain of $1,000 \mathrm{x}$, recordings were made of EMG activity during maximal voluntary contraction at four sites in the muscle belly; 256 potentials were sampled at each site. The density of the interference pattern was measured, with an accuracy of 0.5 $\mathrm{ms}$, in terms of the intervals between successive negative potentials. The differences in potential between successive positive and negative peaks were used in the estimation of the amplitude of the interference pattern. At a gain of $1,000 \mathrm{x}$ the decision level was $50 \mu \mathrm{V}$.

The present examination of the interference pattern differs in two respects from the turns analysis system developed by Willison (Willison, 1964; Rose and Willison, 1967). First, the ANOPS instrument will measure half as many turns since it selects intervals between successive negative peaks only, as opposed to the succeeding negative and positive reversals used in Willison's system. Secondly, we have chosen $50 \mu \mathrm{V}$ rather than $100 \mu \mathrm{V}$ as the decision level for measurement of the amplitude of a deflection (turn). In many cases, however, supplementary analyses were performed at other amplifications. Thus, when the interference pattern was composed entirely of small potentials, as in some patients with myopathy, a preamplifier gain of $5,000 \mathrm{x}$ was employed, the accuracy of measurement then rising to $10 \mu \mathrm{V}$.

\section{RESULTS}

\section{Control Observations}

The mean values for the four muscle action potential parameters are given in Tables 1 and 2 for the pooled population of control muscles. By comparing the standard deviations with the corresponding means, it can be seen that VM showed more variation than BB in relation to measurements of potential durations and of intervals. When patients were examined (see below), this difference between the two muscles may have been partly responsible for the higher incidence of abnormalities detected in BB muscles compared with VM.

In VM muscles of controls, the mean MAP (muscle action potential) durations ranged from 5.4 to $11.2 \mathrm{~ms}$, the overall mean being $8.60 \pm 1.48 \mathrm{~ms}$. For $\mathrm{BB}$, the range was smaller, from 5.6 to $9.0 \mathrm{~ms}$, and the mean value of $7.42 \pm 0.92 \mathrm{~ms}$ was significantly less than the value for VM $(\mathrm{P}=<.005)$. Obviously, had it been possible to compute the gross means from the total number of potentials examined in the control population $(44,032$ potentials from 43 muscles) rather than from the mean for each patient, the level of statistical significance would have been extremely high.

As would be expected on the basis of the simple di- or tri-phasic potential configurations observed on the cathode ray oscilloscope, the mean numbers of phases in the control population of MAPs lay between 2 and 3, being 2.59 for BB and 2.78 for VM. In seven of the 43 muscles, the mean value exceeded 3.0, the largest value being 3.97 for the VM of a 26 year old woman.

The densities of the interference patterns were similar in BB and VM, the respective mean intervals being 4.50

\begin{tabular}{lcccc}
\hline & $\begin{array}{c}\text { DURATION } \\
(\mathrm{ms})\end{array}$ & $\begin{array}{c}\text { PHASES } \\
(\mathrm{no})\end{array}$ & $\begin{array}{c}\text { INTERVAL } \\
(\mathrm{ms})\end{array}$ & $\begin{array}{c}\text { AMPLITUDE } \\
(\mathrm{mV})\end{array}$ \\
\hline CONTROL (22) & $8.60 \pm 1.48$ & $2.78 \pm 0.55$ & $4.96 \pm 1.50$ & $0.78 \pm 0.16$ \\
MYOPATHY (13) & $6.46 \pm 1.60$ & $3.16 \pm 0.79$ & $5.78 \pm 3.61$ & $0.52 \pm 0.30$ \\
& $(<.001)$ & & & $(<.01)$ \\
LIMBGIRDLE & $6.26 \pm 1.89$ & $2.90 \pm 0.68$ & $4.73 \pm 2.21$ & $0.65 \pm 0.22$ \\
DYSTROPHY (8) & $(<.005)$ & & & \\
DENERVATION (21) & $9.18 \pm 1.61$ & $2.86 \pm 0.56$ & $6.10 \pm 1.84$ & $0.72 \pm 0.18$ \\
& & & $(<.05)$ & \\
MOTONEURON DISEASE (8) & $9.24 \pm 2.00$ & $2.70 \pm 0.47$ & $6.25 \pm 2.48$ & $0.84 \pm 0.16$ \\
\hline
\end{tabular}

Table 1. Vastus medialis. Mean MAP parameters ( \pm SD) for controls and patients with myopathies or denervation; significant differences between control and patient means are indicated by probability values below each value. Numbers of patients examined are given in parentheses after each diagnostic category at left.

\begin{tabular}{lcccc}
\hline & $\begin{array}{c}\text { DURATION } \\
(\mathrm{ms})\end{array}$ & $\begin{array}{c}\text { PHASES } \\
(\mathrm{no})\end{array}$ & $\begin{array}{c}\text { INTERVAL } \\
(\mathrm{ms})\end{array}$ & $\begin{array}{c}\text { AMPLITUDE } \\
(\mathrm{mV})\end{array}$ \\
\hline CONTROL $(21)$ & $7.42 \pm 0.92$ & $2.59 \pm 0.40$ & $4.50 \pm 0.90$ & $0.86 \pm 0.15$ \\
MYOPATHY (16) & $5.16 \pm 1.40$ & $2.60 \pm 0.76$ & $5.62 \pm 2.02$ & $0.47 \pm 0.27$ \\
& $(<.001)$ & & $(.05)$ & $(<.001)$ \\
LIMBGIRDLE & $4.83 \pm 0.89$ & $2.68 \pm 0.80$ & $5.58 \pm 2.20$ & $0.42 \pm 0.12$ \\
DYSTROPHY (10) & $(<.001)$ & & & $(<.001)$ \\
DENERVATION (23) & $8.88 \pm 1.85$ & $3.17 \pm 0.82$ & $5.44 \pm 2.14$ & $0.86 \pm 0.17$ \\
& $(<.005)$ & $(<.005)$ & & \\
MOTONEURON & $9.53 \pm 2.16$ & $3.14 \pm 0.78$ & $6.81 \pm 2.56$ & $0.93 \pm 0.21$ \\
DISEASE (9) & $(<.01)$ & & $(<.02)$ & \\
\hline
\end{tabular}

Table 2. Biceps brachii. Mean MAP parameters ( \pm SD) for controls and patients with myopathies or denervation; significant differences between control and patient means are indicated by probability values below each value. Numbers of patients examined are given in parentheses after each diagnostic category at left. 
and $4.96 \mathrm{~ms}$; neither this difference nor that between the mean amplitudes was significant.

The analysis of the data included the calculation of the coefficient of variation (i.e. standard deviation $\div$ mean) for each of the four parameters in all the individuals studied. This analysis was performed in order to detect any muscle in which excessively high incidences of large and small potentials had combined to yield normal mean values. In practice it was found that for each of the parameters there was an approximately linear relationship between the mean and its standard deviation. This relationship was true for the control population and also for most of the muscles of the patients; only one of the 73 muscles in patients would have been recognized as abnormal, using a high coefficient of variation as the sole criterion.

\section{MYOPATHIES}

The durations of the muscle action potentials tended to be shorter in patients with myopathies. This trend was true both for VM and BB and for patients with the limb-girdle, myotonic and Duchenne forms of dystrophy. In $B B$, the incidence of abnormally short potentials was found to be the same whether comparison was made with the lower limit of the observed range of normal results or with a value $2 \mathrm{SD}$ below the control mean. In VM, and for some of the other MAP parameters in both muscles, there were small differences in the incidence of abnormality, depending on which criterion of normality was used (Table 3). We have preferred to use 2 SD above and below the mean as a reference in all subsequent discussion, with the assumption that these limits will include $95 \%$ of the measurements in normal subjects. Of the $29 \mathrm{VM}$ and BB muscles examined, the mean durations fell more than $2 \mathrm{SD}$ below the respective control mean in 15 (Figs. 1 and 2).. The shortest mean duration, $2.79 \mathrm{~ms}$, was found for the VM muscle of a 40 year old man with limbgirdle muscular dystrophy. As a result of this trend, the gross mean durations for the myopathic VM and BB muscles were significantly less than those of the respective controls (Tables 1 and 2). Significant differences could
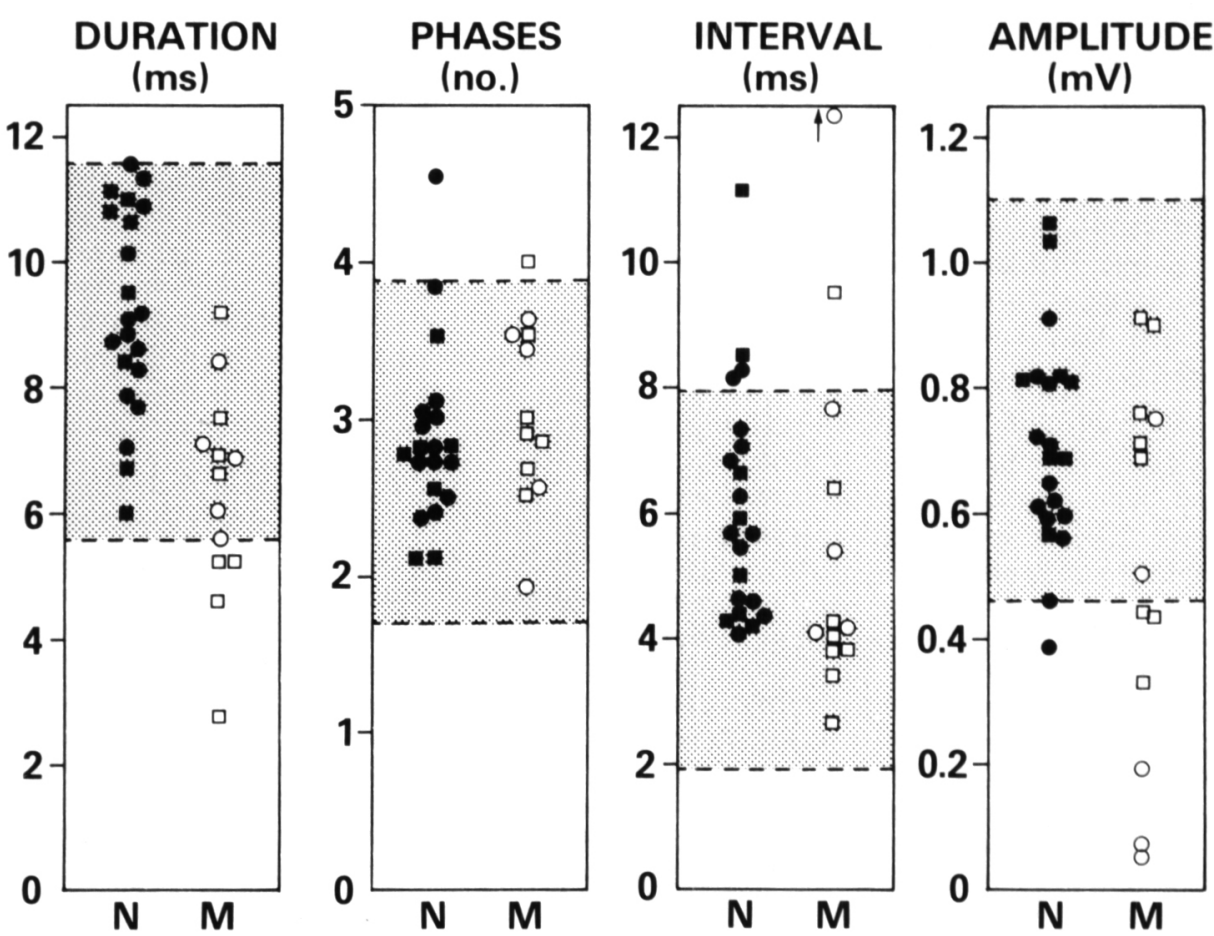

Figure 2-Vastus medialis (VM). Muscle action potential measurements in patients with neuropathic (N) and myopathic (M) disorders; symbols as in Fig. 1.

also be demonstrated for the measurements of amplitude; of the 29 dystrophic BB and VM muscles examined, abnormally small mean amplitudes were found in 18. Although the number of observations is small, it would appear that BB potentials were particularly susceptible to diminution in limbgirdle dystrophy. The smallest mean amplitudes in the present series were found in the two patients with Duchenne muscular dystrophy (Figs. 1 and 2).

In contrast to the measurements of duration and amplitude, the estimations of complexity of the potentials (i.e. polyphasicity) were less consistent in the myopathies. Of the $16 \mathrm{BB}$ muscles examined, excessive values were obtained in 3 while in 4 muscles the values were abnormally short. This last type of result was attributable to the high incidence of small brief potentials which were analysed as being monophasic, since there were no secondary components sufficiently large to reach the threshold for phase detection even when relatively high amplification was used (see Methods). In contrast to the findings for $\mathrm{BB}$, the mean numbers of phases were within the normal range for all but one of the VM muscles examined in the myopathic patients.

The estimations of interference pattern density were significantly diminished in some of the BB muscles, since in 5 of the 16 muscles the mean interval exceeded the upper limit of the control range; two of the 13 myopathic VM muscles exhibited similar behavior. Neither in the BB or the VM muscles, however, did the mean value for the pooled results differ significantly from normal. Unusually short mean intervals were not encountered in any of the 29 $\mathrm{VM}$ and $\mathrm{BB}$ muscles examined.

When the pooled data for the group of patients with limbgirdle dystrophy were examined apart from the remainder, the overall mean durations were significantly reduced both in BB and $\mathrm{VM}$, while the mean amplitude was diminished in BB only. In neither muscle did the mean interval or mean number of phases differ significantly from the respective control means (Tables 1 and 2).

\section{NEUROPATHIES}

Twenty-six patients with denervation had quantitative EMG analyses performed on VM and BB muscles. 
Despite definite clinical evidence of denervation, the EMG findings were commonly within the normal ranges (Figs. 1 and 2). Thus, whereas the mean durations were prolonged in 12 of $23 \mathrm{BB}$ muscles, none of the $21 \mathrm{VM}$ muscles yielded an abnormal result. Within the same samples, excessive mean numbers of phases were found in $9 \mathrm{BB}$ muscles but in only one VM muscle; interference patterns were reduced in $4 \mathrm{BB}$ muscles and in $4 \mathrm{VM}$ muscles. One patient, a 30 year old man in whom the overall EMG picture was suggestive of spinal muscular atrophy, had abnormally brief intervals in BB. The measurements of mean amplitude proved even less satisfactory for detecting denervation, being abnormally large in only one BB and in none of the VM muscles. Abnormally small potentials were recorded in one patient, a 58 year old man with a predominantly axonal type of polyneuropathy of recent onset; the clinical diagnosis of neuropathy was supported by other EMG evidence and by the sensory nerve conduction results. When the mean results for the VM muscles of the patients were pooled, the overall means for each of the four parameters were not significantly different from the corresponding control means. In contrast, the mean duration and mean number of phases of the pooled data for the BB muscles were significantly increased (Table 2). When the pooled results for the group of patients with motoneuron disease were considered separately, the mean values for each of the parameters in the VM muscles did not differ significantly from those of controls. For the BB muscles within the same group, the mean duration and mean intervals were significantly prolonged (Table 2).

Table 3 summarizes the diagnostic usefulness of the ANOPS analysis by showing the incidence of $B B$ and VM muscles which could be recognized as abnormal when all four MAP parameters were considered together.

\section{DISCUSSION}

The ANOPS-101 computer proved easy to use and the EMG examination of a muscle was usually completed in less than 10 minutes, including the time required for plotting out the frequency histograms and for calculating the

\begin{tabular}{llllllllllll}
\hline \multicolumn{1}{c}{ DURATION PHASES } & \multicolumn{1}{c}{ INTERVAL } & AMPLITUDE & \multicolumn{3}{c}{ ALL PARA } \\
METERS
\end{tabular}

Table 3. Percentage abnormalities in terms of control ranges (R) or control means $\pm 2 S D$. Higher incidence of abnormalities in biceps brachii relative to vastus medialis is significant both for patients with myopathies $\left(P=.01 ; x^{2}=6.50\right)$ and for those with neuropathies $\left(P=.001 ; x^{2}=10.83\right)$. The two columns at the right give cumulative incidences of abnormal muscles using all four parameters.

mean and standard deviation for each of the four MAP parameters. Of the control results, those which can be most readily compared with previously published values are the measurements of duration. The mean values of 7.42 and $8.60 \mathrm{~ms}$ for $\mathrm{BB}$ and $\mathrm{VM}$ respectively are both about one third less the values obtained by Buchthal (1957) for adults of comparable ages. There are at least three factors which will have contributed to this discrepancy. One is the ANOPS computer itself, since the incorporation of a low frequency filter would effectively shorten measurements of duration for those potentials with slow onsets or terminations. A second factor is that the duration of a potential is not measured from the base line but from a $20 \mu \mathrm{V}$ detection level. Finally, the apparent duration of a normal potential increases with its amplitude (see Kopec and Hausmanowa-Petrusewicz, 1976) and in the present study no attempt was made to manipulate the electrode tip until the maximum amplitude of a potential had been reached. This policy was adopted to avoid the possibility of inadvertently biasing the recording towards the type of EMG activity which would have been anticipated on the basis of the clinical diagnosis. In this respect our technique differs from that of Kopec and HausmanowaPetrusewicz (1976) and of the Copenhagen group of electromyographers (e.g. FuglsangFrederiksen and Mansson, 1975) who have sought optimal electrode positions for their analyses.

Turning to the pathological material, the computer proved able to demonstrate that more than half of the MAP parameters measured in myopathic BB muscles were abnormal
(35 abnormalities in 64 observations). The corresponding yield for VM was much lower, comprising only 13 abnormalities in 52 observations; this difference between the two muscles was statistically significant $(P=<.01)$. In keeping with conventional interpretation of the EMG, the MAPs in the myopathic patients tended to be smaller and briefer than normal. A point of disagreement was that the mean number of phases were sometimes significantly reduced, since many of the small brief potentials were virtually monophasic with very small additional components. Also in conflict with interpretative theory was the finding of reduced interference pattern densities in some of the muscles. This finding, if considered in isolation, would have caused confusion by suggesting the presence of denervation. If the interference pattern density results were excluded, 14 of the $16 \mathrm{BB}$ muscles could be identified as myopathic on the basis of one or more of the three remaining parameters being abnormal; for VM the corresponding yield was 7 out of 13 muscles (Table 3).

The present results may be compared with those of FuglsangFrederiksen, Scheel and Buchthal (1976) who used the automatic system of Rose and Willison (1967) to count the numbers and amplitudes of potential reversals (turns) in the interference pattern. These authors examined BB muscles in 41 patients of whom 26 had muscular dystrophy. Unlike the present study, in which maximal contractions were used for analysis of the interference patterns, that of FuglsangFrederiksen et al (1976) required patients to generate forces which were 30 percent maximal. These authors found that the most satisfactory index 
of abnormality was an increase in the ratio of turns frequency to mean amplitude; this measurement enabled 71 percent of the patients to be identified as having myopathies. Willison (1964), performing the same type of analysis from photographic records, also found increases in turns frequency in most patients with myopathies.

It is interesting that FuglsangFrederiksen et al (1976), like ourselves, observed that the density of the interference pattern, as given by the turns frequency, was reduced in a proportion of the patients with myopathic disorders. Fuglsang-Frederiksen et al attributed this finding to severe losses of muscle fibers resulting in the total destruction of motor units. Such an interpretation would be in keeping with the finding of reduced counts of motor units in dystrophy by McComas, Sica and Campbell (1971) who used an incremental stimulating technique. The present results differ sharply from those of Fuglsang-Frederiksen et al in that the amplitudes of the MAPs were commonly reduced in the former study but not in the latter. While it is true that we did not measure the amplitudes of single MAPs, the finding of a low mean amplitude of the turns in the interference pattern, together with a normal or reduced density (a combination also encountered by FuglsangFrederiksen et al), is most readily interpreted in terms of small individual MAPs. In the present study, the MAPs in some myopathic patients were so small that increased amplification was necessary for measurement of the durations and phases (see Methods).

The results of testing muscles in patients with neuropathies were much less satisfactory. Of the $21 \mathrm{VM}$ muscles studied, only 4 yielded one or more normal parameters. While the severity of denervation in patients with clinical and radiological evidence of lumbar root disease is open to question, it should be noted the 6 of the 8 patients with quite advanced motoneuron disease yielded normal results in VM. Examinations of BB muscles in these patients was more productive since 15 of 23 muscles could be recognized as abnormal. In 12 of the abnormal BB muscles, the mean duration exceeded the control range and in 9 muscles the mean number of phases was increased.
Investigation of the interference pattern, either for density or for amplitude, was much less useful. In this last respect our findings differ from those obtained by Hayward and Willison $(1973,1977)$ who, in a careful quantitative study, found approximately half of their patients with motoneuron disease to have VM muscles yielding mean turn amplitudes outside the control range. The difference may lie in the fact that these authors required their subjects to generate isometric tensions which were approximately $20 \%$ of the maximum value for controls. In the present study, the use of stronger contractions would have recruited those high threshold motor units in the control muscles with sizes comparable to the large motor units found in chronic neuropathies. Thus in BB and VM muscles of controls, the mean amplitudes measured from the interference pattern are more than twice as large in the present study as in those of Hayward and Willison, even though we have included deflections as small as $50 \mu \mathrm{V}$ for measurement (as opposed to the $100 \mu \mathrm{V}$ limit of Hayward and Willison). Results were also obtained using $100 \mu \mathrm{V}$ as the lower limit (decision level) but have not been plotted in the figures; the mean amplitudes were approximately half as large again as those measured for a decision level of $50 \mu \mathrm{V}$.

Fuglsang-Frederiksen, Scheel and Buchthal (1977) have also studied chronic partial denervation using turns analysis; as in their investigation of myopathies (Fuglsang-Frederiksen et al, 1976) these authors required their patients to exert forces which were 30 percent maximal. Unlike Hayward and Willison (1973, 1977), FuglsangFrederiksen et al (1977) found that a reduction in turns frequency was the most sensitive indication of denervation, being present in $70 \%$ of their patients. Turns amplitudes were less commonly elevated, but were sometimes present in patients with normal turns frequencies. In analysing possible mechanisms for their results, Fuglsang-Frederiksen (1977) cooled normal biceps muscles; it may be pointed out that the authors do not appear to have taken into consideration the reduction in tetanus fusion frequency which would have occurred at the lower temperatures.

In relation to the usefulness of the ANOPS system, it is possible that a higher yield of abnormalities in patients with denervation would have been achieved if measurements of amplitude had been made of single MAPs during weak voluntary contraction rather than of the turns in the interference pattern (see also Kopec and HausmanowaPetrusewicz, 1976). An additional analysis of this kind would have meant either repeating the electrode insertions in each muscle or alternatively replaying the activity recorded on magnetic tape during weak contraction through the amplitude mode as well as through the duration and phases mode. Although either procedure would have reduced the speed and convenience of the analytical technique, it may prove necessary for one of these to be included in a future protocol. It should be emphasized that although the detection of abnormal muscles is improved by combining the results for the four MAP parameters (see Table 3), the likelihood of false positive results is raised fourfold; this aspect is discussed by McComas and Sica (1978).

A final point, of some practical consequence, is that the BB muscle emerged in the study as being more likely to show abnormality than the $V M$ in both myopathic and neuropathic disorders.

\section{ACKNOWLEDGEMENTS}

Our thanks are due to Dr. S. J. Kopec and Dr. J. Delbeke for their invaluable help at the start of this study and to Dr. C. Dunnett for statistical advice. Heidi Roth and Glenn Shine provided technical assistance and Norma Zimmerman kindly typed the manuscript. 


\section{REFERENCES}

BUCHTHAL, F. (1957). An Introduction to Electromyography. Oslo: Scandinavian University Books.

CAMPBELL, M. J., McCOMAS, A. J. and PETITO, F. (1973). Physiological changes in ageing muscles. Journal of Neurology, Neurosurgery and Psychiatry, 36, 174-182.

FUGLSANG-FREDERIKSEN, A. and MANSSON, A. (1975). Analysis of electrical activity of normal muscle in man at different degrees of voluntary effort. Journal of Neurology, Neurosurgery and Psychiatry, 38, 683-694.

FUGLSANG-FREDERIKSEN, A., SCHEEL, U. and BUCHTHAL, F. (1976). Diagnostic yield of analysis of the pattern of electrical activity and of individual motor unit potentials in myopathy. Journal of Neurology, Neurosurgery and Psychiatry, 39, 742-750.

FUGLSANG-FREDERIKSEN, A., SCHEEL, U. and BUCHTHAL, F. (1977). Diagnostic yield of the analysis of the pattern of electrical activity of muscle and of individual motor unit potentials in neurogenic involvement. Journal of Neurology, Neurosurgery and Psychiatry, 40, 544-554.
HAYWARD, M. and WILLISON, R. G (1973). The recognition of myogenic and neurogenic lesions by quantitative EMG. In New Developments in Electromyography and Clinical Neurophysiology. ed. J. E. Desmedt, vol. 2, pp. 448-453. Basel: Karger.

HAYWARD, $M$. and WILLISON, R. G. (1977). Automatic analysis of the electromyogram in patients with chronic partial denervation. Journal of the Neurological Sciences, 33, 415-423.

KOPEC, J, and HAUSMANOWAPETRUSEWICZ, I. (1976). On-line computer application in clinical quantitative electromyography. Electromyography and Clinical Neurophysiology, 16, 49-64.

KOPEC, J., HAUSMANOWAPETRUSEWICZ, I., RAWSKI, M. and WOLYNSKI, M. (1973). Automatic analysis in electromyography. In New Developments in Electromyography and Clinical Neurophysiology. ed. J. E. Desmedt, vol. 2, pp. 447-481. Basel : Karger.

KUNZE, K. (1973). Quantitative EMG analysis in myogenic and neurogenic muscle diseases. In New Developments in Electromyography and Clinical Neurophysiology. ed. J. E. Desmedt, vol. 2, pp. 469-476. Basel : Karger.
LEE, R. G. and WHITE, D. G. (1973). Computer analysis of motor unit action potentials in routine clinical electromyography. In New Developments in Electromyography and Clinical Neurophysiology. ed. J. E. Desmedt, vol. 2, pp. 454-461. Basel : Karger.

McCOMAS, A. J. and SICA, R. E. P. (1978). Automatic quantitative analysis of the electromyogram in partially denervated distal muscles: a comparison with motor unit counting. Canadian Journal of Neurological Sciences. In press.

McCOMAS, A. J., SICA, R. E. P. and CAM PBELL, M. J. (1971). 'Sick' motoneurones. A unifying concept of muscle disease. Lancet, 1. 321-325.

ROSE, A. L. and WILLISON, R. G. (1967). Quantitative electromyography using automatic analysis: studies in healthy subjects and patients with primary muscle disease. Journal of Neurology, Neurosurgery and Psychiatry, 30, 403-410.

WALTON, J. N. (1952). The electromyogram in myopathy. Analysis with the audiofrequency spectrometer. Journal of Neurology, Neurosurgery and Psychiatry, 15, 219-226.

WILLISON, R. G. (1964). Analysis of electrical activity in healthy and dystrophic muscle in man. Journal of Neurology, Neurosurgery and Psychiatry, 27, 386-394. 